\title{
Cued fear memory generalization increases over time
}

\author{
Gabrielle A. Pollack, Jessica L. Bezek, Serena H. Lee, Miranda J. Scarlata, Leah T. Weingast, \\ and Hadley C. Bergstrom \\ Department of Psychological Science, Program in Neuroscience and Behavior, Vassar College, Poughkeepsie, New York 12604 USA
}

\begin{abstract}
Fear memory is a highly stable and durable form of memory, even over vast (remote) time frames. Nevertheless, some elements of fear memory can be forgotten, resulting in generalization. The purpose of this study is to determine how cued fear memory generalizes over time and measure underlying patterns of cortico-amygdala synaptic plasticity. We established generalization gradients at recent (1-d) and remote (30-d) retention intervals following auditory cued fear conditioning in adult male C57BL/6 mice. Results revealed a flattening of the generalization gradient (increased generalization) that was dissociated from contextual fear generalization, indicating a specific influence of time on cued fear memory performance. This effect reversed after a brief exposure to the novel stimulus soon after learning. Measurements from cortico-amygdala imaging of the activity-regulated cytoskeletal Arc/arg 3.1 (Arc) protein using immunohistochemistry after cued fear memory retrieval revealed a stable pattern of Arc expression in the dorsolateral amygdala, but temporally dynamic expression in the cortex. Over time, increased fear memory generalization was associated with a reduction in Arc expression in the agranular insular and infralimbic cortices while discrimination learning was associated with increased Arc expression in the prelimbic cortex. These data identify the dorsolateral amygdala, medial prefrontal, and insular cortices as loci for synaptic plasticity underlying cued fear memory generalization over time.
\end{abstract}

[Supplemental material is available for this article.]

Of all memory types, threat/aversive (fear) conditioning is thought to be one of the most durable and change-resistant (Bergstrom 2016). Fear conditioning is a form of associative learning in which a sensory stimulus is paired with an unconditioned stimulus (US) that naturally evokes a defensive physiological response. Through pairing, the conditioned stimulus (CS) gains the ability to elicit a conditioned response (CR) in the absence of the US. While fear memories are thought to be highly stable (Gale et al. 2004), some elements can change, resulting in generalization (Jasnow et al. 2016). Generalization is defined as responding to stimuli that resemble those present during acquisition. For example, once a stimulus has been conditioned, generalization refers to the spread of responding to new stimuli that are perceptually like the original CS (Pearce 1987). Generalization is conceptualized as a form of forgetting (Jasnow et al. 2012), considered an active memory process that contributes to behavioral flexibility (Richards and Frankland 2017) and a fundamental property of learning and memory (Shepard 1987).

A parameter that determines the extent of CS generalization is the duration between training and testing (Perkins and Weyant 1958; McAllister and McAllister 1963; Riccio et al. 1992; Bouton et al. 1999). That is, generalization tends to increase with the passage of time. Most studies of fear memory generalization processes over time have focused on contextual fear conditioning (Balogh et al. 2002; Wiltgen and Silva 2007; Cullen et al. 2015; Poulos et al. 2016). It is widely accepted that common, and distinct, neuronal circuits encode and store contextual and cued fear memory (Phillips and LeDoux 1992). Though it is established that recently formed cued fear memories generalize (Armony et al. 1997; Laxmi et al. 2003; Ito et al. 2009; Xu and Sudhof 2013), study of cued fear memory generalization over time has been neglected (Thomas and Riccio 1979), and its organization in the brain remains largely un-

Corresponding author: habergstrom@vassar.edu

Article is online at http://www.learnmem.org/cgi/doi/10.1101//m.047555.118. known. The purpose of this study is to characterize cued fear memory generalization and associated cortico-amygdala patterns of synaptic plasticity over time. How ongoing consolidation processes over time relate to memory performance is a key question in memory neuroscience (Hardt and Nadel 2017). The study of fear generalization also has relevance to human health. While fear generalization itself is thought to be adaptive, overgeneralization of fear is maladaptive and considered a central symptomatic dimension of post-traumatic stress disorder (PTSD) and anxiety-related disorders (Lissek 2012; Dunsmoor and Paz 2015; Morey et al. 2015; Lopresto et al. 2016).

Stimulus discrimination and generalization can be systematically tested and graphically represented by constructing a stimulus generalization gradient (Guttman and Kalish 1956; Thomas et al. 1960). The shape of the gradient reflects the degree of stimulus discrimination and generalization. Stimuli that are perceptually similar to the CS elicit the strongest CRs, and stimuli perceived as dissimilar from the CS elicit weaker CRs, thus forming a sloping gradient of generalization. Steeper curves reflect more discrimination while flatter curves reflect generalization. Here we constructed a generalization gradient for cued fear memory over time by fear conditioning all mice at a single frequency of auditory stimulus (i.e., the "target" stimulus). We then tested each subject with a separate stimulus along a parametrically varied test dimension at a recent or remote time point in a between-subject design. We also incorporated a within-subject design to test whether discrimination training soon after learning improves stimulus control (discrimination) over time.

(C) 2018 Pollack et al. This article is distributed exclusively by Cold Spring Harbor Laboratory Press for the first 12 months after the full-issue publication date (see http://learnmem.cshlp.org/site/misc/terms.xhtml). After 12 months, it is available under a Creative Commons License (Attribution-NonCommercial 4.0 International), as described at http://creativecommons.org/licenses/by-nc/ $4.0 \%$. 
To examine cortico-amygdala patterns of synaptic plasticity, we used immunohistochemistry to visualize the activity-regulated cytoskeletal protein Arc/arg 3.1 (Arc) (Lyford et al. 1995), following cued fear memory retrieval at recent and remote time points following learning (Mamiya et al. 2009; GoutyColomer et al. 2015; Cho et al. 2016; Gruene et al. 2016; Morrison et al. 2016; Nakayama et al. 2016). Arc protein is necessary for memory formation (Plath et al. 2006; Ploski et al. 2008), and memory reconsolidation (Maddox and Schafe 2011) and has been implicated in both long-term potentiation (LTP) (Guzowski et al. 2000) and long-term depression (LTD) processes (Waung et al. 2008). Therefore, we interpreted the presence of Arc immunoreactivity in neurons following cued fear memory retrieval as a marker for synaptic plasticity associated with memory consolidation (Shepherd and Bear 2011).

Arc expression was mapped and quantified in an a priori determined brain system implicated in remote auditory cued fear memory retrieval, generalization, and discrimination: the dorsolateral amygdala (LAd), prelimbic cortex (PL), infralimbic cortex (IL), temporal association cortex (TeA), and posterior agranular insula (AIP) (Sacco and Sacchetti 2010; Kwon et al. 2012; Xu and Sudhof 2013; Fitzgerald et al. 2014; Do-Monte et al. 2015; Cambiaghi et al. 2016; Cho et al. 2016; Kim and Cho 2017). Multivariate statistics followed by discriminant function analyses (DA) were applied to dissect the relative contribution of Arc expression in the LAd, PL, IL, TeA, and AIP to fear memory performance (generalization and discrimination) over time.
A
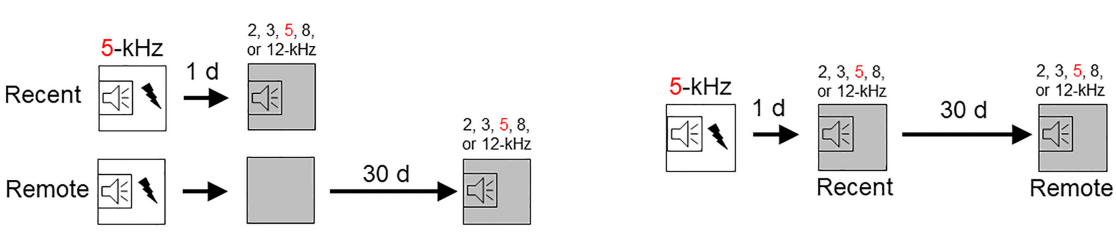

C

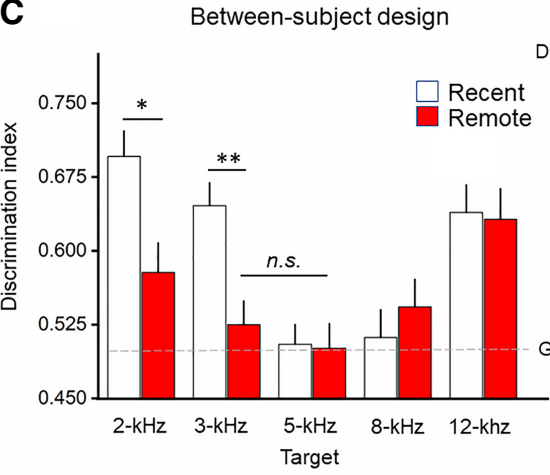

D

Within-subject design

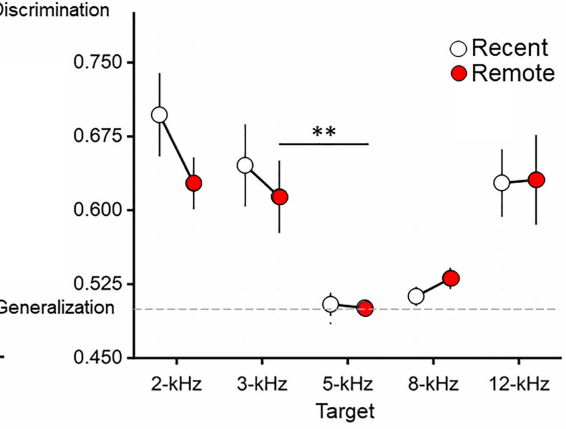

E

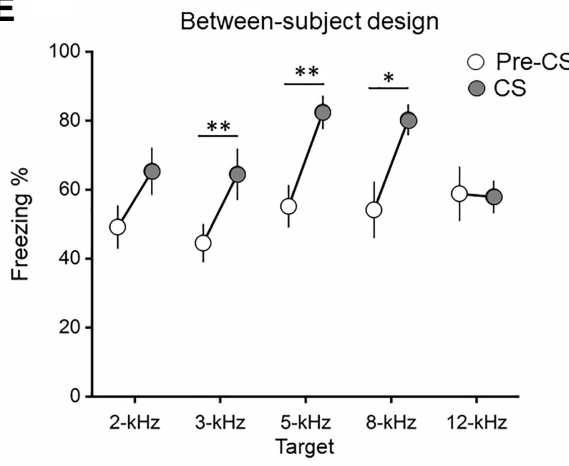

$\mathbf{F}$

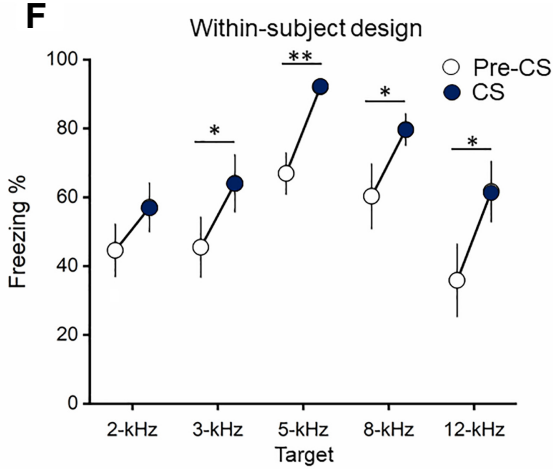

Figure 1. Cued fear memory generalization increases over time. $(A, B)$ Schematics of between- and within-subject designs. Open squares represent the training environment and gray squares represent the testing environment. $(C, D)$ There was more generalization in the between-subject design compared with the within-subject design. At the remote time point, freezing in the $3-\mathrm{kHz}$ group was equivalent (n.s.) to the $5-\mathrm{kHz}$ target in the between-subject design. A discrimination index approaching 0.5 indicates generalization (dashed line) and a discrimination index approaching 1 indicates discrimination. $(E, F)$ CS-elicited freezing was elevated above contextual freezing (Pre-CS, $20 \mathrm{sec}$ immediately prior to CS). $n=10-22$ / group. Symbols and bars are mean \pm SEM. $\left(^{*}\right) P<0.05,\left(^{* *}\right) P<0.01$.

\section{Results}

\section{Experiment 1: between-subjects}

In the between-subjects design, two-way ANOVA revealed a significant $\mathrm{kHz} \times$ Time interaction on the discrimination index $\left(F_{(4,122)}=3.7 ; P=0.007\right)$. At the recent time point, mice discriminated the $2-\mathrm{kHz}(P=0.001), 3-\mathrm{kHz}(P=0.005)$, and $12-\mathrm{kHz}(P=0.05)$ stimulus test frequencies from the $5-\mathrm{kHz}^{\text {"target" }}$ stimulus frequency, suggesting that for most of the tone frequencies tested mice can retain a discriminate memory for the original frequency of the CS (Fig. 1). There was no difference in discrimination index between the 8 - and $5-\mathrm{kHz}$ frequency, indicating a sharp degree of cued fear memory generalization for the $8-\mathrm{kHz}$ frequency at the recent time point. At the remote time point, the discrimination index between the $3-\mathrm{kHz}$ versus $5-\mathrm{kHz}$ groups was statistically equivalent, indicating a high degree of generalization at the remote time point for the $3-\mathrm{kHz}$ stimulus. There were differences in the discrimination indices detected between the $5-\mathrm{kHz}$ versus $2-\mathrm{kHz}(P<0.05)$ and $12-\mathrm{kHz}(P<0.001)$ groups, indicating discrimination of the 2 - and $12-\mathrm{kHz}$ tone frequencies, even over long periods of time. There was also no significant difference in the freezing response be- tween the $5-\mathrm{kHz}$ stimulus at recent and remote timepoints, with a coefficient of variation of 0.22 at the recent time point and a coefficient of variance of 0.05 at the remote time point. Together, these data suggest a high degree of stability in response to the target $5-\mathrm{kHz} \mathrm{CS}$ over time. Overall, these data suggest that presentation of a novel, 3-kHz stimulus at a recent time point can be discriminated. However, over time, presentation of the novel, $3-\mathrm{kHz}$ stimulus produces a generalized CR. At a frequency range farther away from the target stimulus (2- and $12-\mathrm{kHz}), \mathrm{CRs}$ remain discriminable. Overall, these data demonstrate increased cued fear memory generalization over time as depicted by a flattening of the generalization gradient (Fig. 1). Raw CS-freezing levels are plotted in Supplemental Figure S1.

\section{Experiment 2: within-subject}

In the within-subjects design, repeated measures ANOVA revealed a significant main effect of $\mathrm{kHz}$ on the discrimination index $\left(F_{(4,47)}=\right.$ 8.8; $P<0.001)$. There were no significant within-subject effects (Time), indicating no changes in freezing responses over time 
(Fig. 1). Bonferroni post-hoc analysis revealed significantly more discrimination in the $2-\mathrm{kHz}(P<0.001), 3-\mathrm{kHz}(P=0.01)$, and $12-\mathrm{kHz}(P=0.004)$ group relative to the $5-\mathrm{kHz}$ target stimulus, indicating that in a within-subject design, mice discriminated 2-, 3-, and $12-\mathrm{kHz}$ stimuli at both recent and remote timepoints. There were no statistically significant differences in freezing between the 8- and $5-\mathrm{kHz}$ stimuli $(P>0.05)$, indicating that mice generalize the $8-\mathrm{kHz}$ stimulus at both the recent and remote time points. Conditioned freezing to the target stimulus remained relatively stable over time with a coefficient of variation of 0.22 at the recent time point and a coefficient of variance of 0.03 at the remote time point. Raw freezing values are provided in Supplemental Figure S1.

\section{Contextual fear generalization}

To address the question of how contextual freezing contributes to cued freezing, pre-CS freezing (180 sec) in the training and testing environments was first measured across testing phases (preTraining, pre-Recent CS, pre-Remote CS). Results revealed a robust increase in contextual freezing over time (Supplemental Results; Supplemental Fig. S2). This result supports previous work showing greater contextual freezing with the passage of time (Wiltgen and Silva 2007; Poulos et al. 2016).

To determine the precise relationship between contextual freezing and cued freezing, the freezing response was measured immediately preceding the presentation of the CS for the equivalent duration as the CS $(20 \mathrm{sec})$. The freezing measure (Pre-CS and CS) was then statistically compared using repeated-measures ANOVA followed by paired $t$-tests. In the remote between-subjects design group, repeated measures ANOVA revealed a main effect of Time (Pre-CS to CS) $\left(F_{(1,52)}=30.7 ; P<0.001\right)$ but no interaction with $\mathrm{kHz}$. Subsequent paired $t$-test (Pre-CS to CS) showed significant increases in freezing from Pre-CS to CS in the $3-\mathrm{kHz}(P=0.002), 5-\mathrm{kHz}$ $(P=0.003)$, and $8-\mathrm{kHz}(P=0.045)$ groups. In the remote withinsubject design, repeated-measures ANOVA revealed a main effect of Time (Pre-CS to CS) $\left(F_{(1,56)}=41.7 ; P<0.001\right)$ but no interaction with $\mathrm{kHz}$. Follow-up paired $t$-test showed significant increases in freezing from Pre-CS to CS in the $3-\mathrm{kHz}$ $(P=0.029), 5-\mathrm{kHz}(P=0.001), 8-\mathrm{kHz}(P=$ $0.026)$, and $12-\mathrm{kHz}(P=0.011)$ groups. Together, these results show that cued freezing was significantly greater than baseline for a majority of the tone frequency groups, suggesting the context shift from training to testing was sufficient to isolate, at least a portion of, the expression of CS-specific freezing. To test the influence of the context shift at the recent time point (i.e., the between-subjects design) on cued and context generalization at a remote time point, we added another experimental group that was not exposed to the novel context at a recent time point. Results revealed equivalent remote contextual and cued freezing, indicating the context shift soon after learning was sufficient to reduce generalized contextual freezing over time (Supplemental Fig. S3).

\section{Cortico-amygdala Arc expression over time}

MANOVA revealed a significant interaction of Time $\times \mathrm{kHz}\left(V=0.54, F_{(20,220)}=\right.$ $1.7 ; P=0.03)$. Follow-up ANOVAs re- vealed significant $\mathrm{kHz} \times$ Time interactions in the PL $\left(F_{(4,56)}=6.3\right.$; $P=0.004)$ and IL $\left(F_{(4,56)}=3.5 ; P=0.01\right)$. In the PL, Arc expression was greater in the $5-\mathrm{kHz}$ compared with the $3-\mathrm{kHz}(P=0.02)$ and Control $(P=0.02)$ groups at the recent time point. At the remote time point in the between-subjects design, there were no differences between groups. At the remote time point in the within-subject design, there was greater $\operatorname{Arc}$ expression in the $3-\mathrm{kHz}$ relative to Control group $(P=0.03)$. Together, these data show fear memory retrieval-induced plasticity in the PL changing over time (Fig. 2). In the IL, there were no changes in Arc expression at the recent and remote within-subject group. However, in the remote betweensubject group there was less Arc expression in the 3-kHz group compared with Control $(P=0.01)$ (Fig. 2). Together, these findings suggest a dichotomous pattern of fear memory retrieval-induced Arc expression in the PL and IL that changes with the passage of time. MANOVA also revealed a main effect of $\mathrm{kHz}(V=0.67$, $\left.F_{(10,106)}=5.5 ; P<0.001\right)$. Follow-up ANOVAs revealed effects of $\mathrm{kHz}$ in the LAd only $\left(F_{(2,56)}=10.1 ; P<0.001\right)$ (Fig. 3$)$. There was significantly greater $\operatorname{Arc}$ expression in the $3-\mathrm{kHz}(P=0.007)$ and $5-\mathrm{kHz}$ $(P<0.001)$ groups versus control.

Next, we followed-up the MANOVA with DA to understand the nature of the relationship among cortico-amygdala regions expressing Arc and how the relationship predicts memory performance (discrimination or generalization) at different time points following learning. DA revealed a pattern of Arc expression in the LAd and PL contributed most to fear memory expression at a recent time following learning (Supplemental Results; Supplemental Fig. S5). This same pattern reemerged at the remote time point following learning in the within-subject design. These results confirm that memory precision over time is associated with a pattern of Arc expression in the LAd and PL.

In the remote between-subjects design, fear memory generalization over time was associated with a pattern of Arc expression in the AIP and IL (Figs. 2, 4; Supplemental Results; Supplemental Fig. S5). This result prompted a post-hoc analysis of Arc expression in the AIP (see above for IL results). One-way ANOVA on Arc expression in the AIP revealed a significant effect of $\mathrm{kHz}\left(F_{(2,19)}=16.6\right.$;
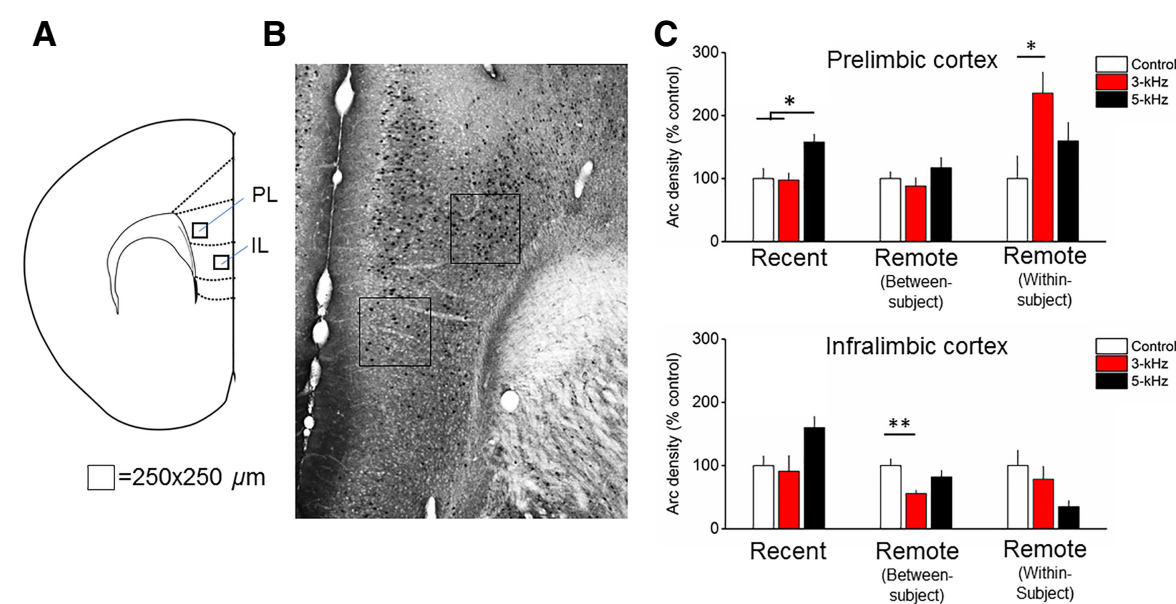

Figure 2. Arc expression following cued fear memory retrieval at recent and remote time points in the prelimbic (PL) and infralimbic (IL) subregions of the medial prefrontal cortex. $(A)$ Atlas image depicting the relative location of the counting frames in the PL and IL. In the PL, the counting frame was located in deep layers. In the IL, the counting frame was positioned in shallow layers. $(B)$ Representative micrograph depicting Arc immunohistochemistry and counting frame $\left(250 \mu \mathrm{m}^{2}\right)$. (C) In the PL, Arc expression was greater at the recent time point in the $5-\mathrm{kHz}$ group compared with the $3-\mathrm{kHz}$ group and control. At the remote time point in the within-subject design (discrimination), Arc expression in the 3-kHz group was greater than control but not different from the 5-kHz group. In the IL, Arc expression was reduced in the $3-\mathrm{kHz}$ group compared with controls in the remote between-subject design (generalization). $n=7-8$ / group, bars are mean \pm SEM. $\left(^{*}\right) P<0.05$ and $\left({ }^{* *}\right) P<0.01$. 
A
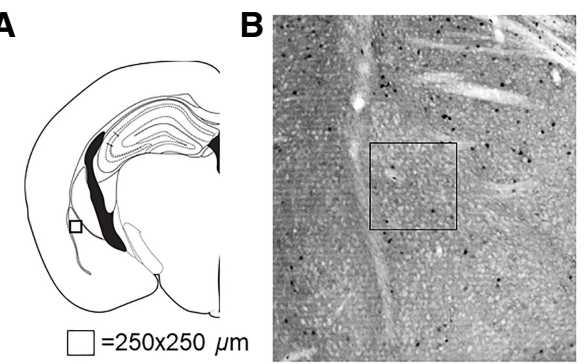

c

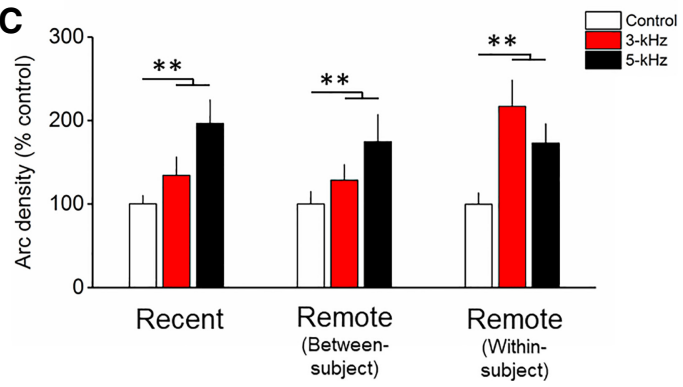

Figure 3. Arc expression following cued fear memory retrieval at recent and remote time points in the dorsolateral amygdala (LAd). (A) Atlas depicting the relative location of the counting frame in the LAd. (B) Representative micrograph depicting Arc immunohistochemistry and counting frame (250 $\mu^{2}{ }^{2}$ ). (C) Arc expression did not differ between 3- and 5-kHz groups but was significantly increased compared with the control group $(n=8)$, and was stable over time. Bars represent mean \pm SEM. $n=7-8 /$ group $^{\left({ }^{*}\right)}$ $P<0.01$.

$P<0.001)$, with reduced Arc expression following presentation of the $3-\mathrm{kHz}(P<0.001)$ and $5-\mathrm{kHz}(P=0.001)$ tone compared to control (Fig. 4). Finally, neither MANOVA or DA uncovered effects of $\mathrm{kHz}$ in the TeA (Fig. 5; Supplemental Fig. S5), although there were effects of Time (Supplemental Results). Raw Arc density values are provided in Supplemental Figure S4. Overall, results suggest a reorganization of cued fear memory generalization and discrimination circuit plasticity over time.

\section{Discussion}

When confronted with an environmental stimulus that ambiguously signals threat, generalization of a previously learned defensive response may be advantageous. Here, we report a classical "steep" generalization gradient for an auditory cued fear memory tested 24-h following learning, with low CRs to stimuli that least resemble the CS and high CRs to stimuli that most resemble the CS. Over time, the gradient "flattened," with higher CRs to stimuli nearer in perceptual similarity to the CS. Specifically, after a 30-d retention interval, mice exhibited an equivalent $C R$ to a novel ("nontarget") 3-kHz tone and the "target" 5-kHz CS in a betweensubject design. In a within-subject design, mice presented with a nontarget tone stimulus soon after conditioning (24-h) regained stimulus control when presented with the same stimulus at the remote time point, suggesting new learning about the nontarget stimulus retrieval cue persisted over at least $30-\mathrm{d}$. The remote cued freezing responses were elevated above baseline, indicating that time exerts a unique influence on the generalization of discrete tone conditioned stimuli. Notably, CRs to the original "target" CS remained remarkably stable over time. Taken together, these results indicate that while cued fear memory performance is highly stable over long time frames, some elements of performance may also change.
To address the question of how distributed, systems-level, changes in neuronal synaptic plasticity relate to memory performance with the passage of time, we used immunohistochemistry with an antibody against the activity-regulated cytoskeletal-associated protein $(A r c)$ to visualize learning-induced synaptic plasticity in neurons across a predefined cortico-amygdala network following recent and remote cued fear memory retrieval. Arc imaging revealed a stable pattern of plasticity in the LAd over time, while more temporally dynamic changes occurred in the cortex depending on prior experimental experience. Increased fear memory generalization (in a between-subject design) was associated with decreased Arc expression in the AIP and IL, while discrimination training (in a within-subject design) was associated with elevated Arc expression in the PL. This pattern of cortico-amygdala neuronal ensemble rearrangement underlying cued fear memory supports systems consolidation models suggesting the retrieval of old memories engages cortical circuits (Wiltgen et al. 2004). Considering that stimuli rarely occur in the same form, arrangement or context from one circumstance to the next, an active process of generalization over time would serve an important adaptive function in an ever-changing environment (Richards and Frankland 2017).

\section{Cued fear memory generalization}

Across all memory phases, LAd Arc expression in response to the nontarget stimulus was consistently greater than background but indistinguishable from the target stimulus, suggesting that plasticity in the LAd remained engaged over time but unresponsive to the frequency of the tone (Table 1; Fig. 3). These findings conflict with several studies indicating a role for the amygdala in tone frequency
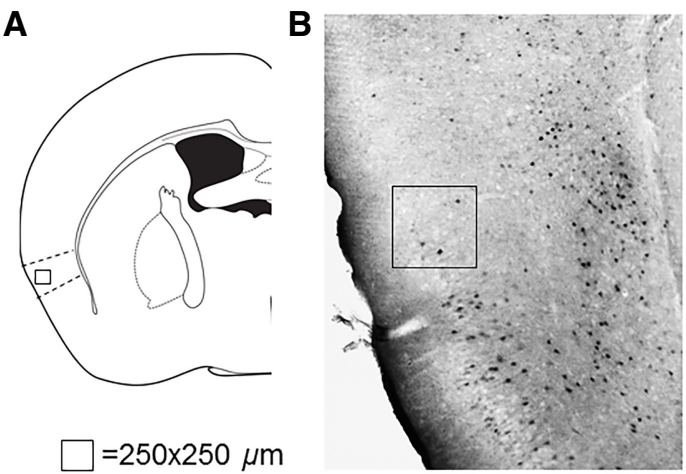

C

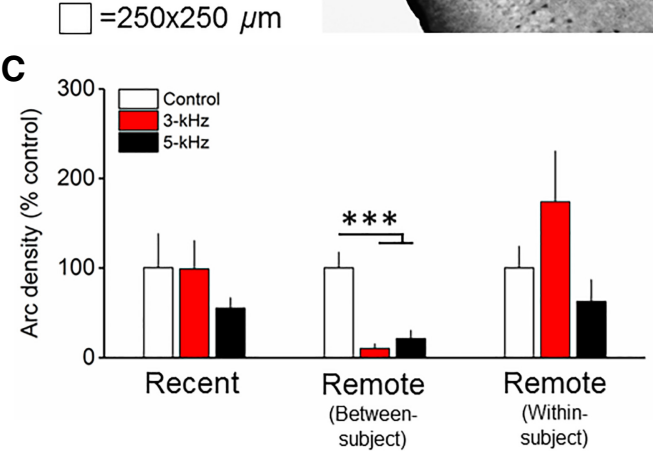

Figure 4. Arc expression following cued fear memory retrieval at recent and remote time points in the AIP. (A) Atlas image depicting the relative location of the counting frame in the AIP. (B) Representative micrograph depicting Arc immunohistochemistry and counting frame $\left(250 \mu \mathrm{m}^{2}\right)$. (C) At the remote time point in the between-subject design (generalization), Arc expression was significantly reduced in the $5-$ and $3-\mathrm{kHz}$ groups compared to the control. $n=7-8$ /group, bars are mean \pm SEM. $\left({ }^{* * *}\right) P<0.001$ 
A
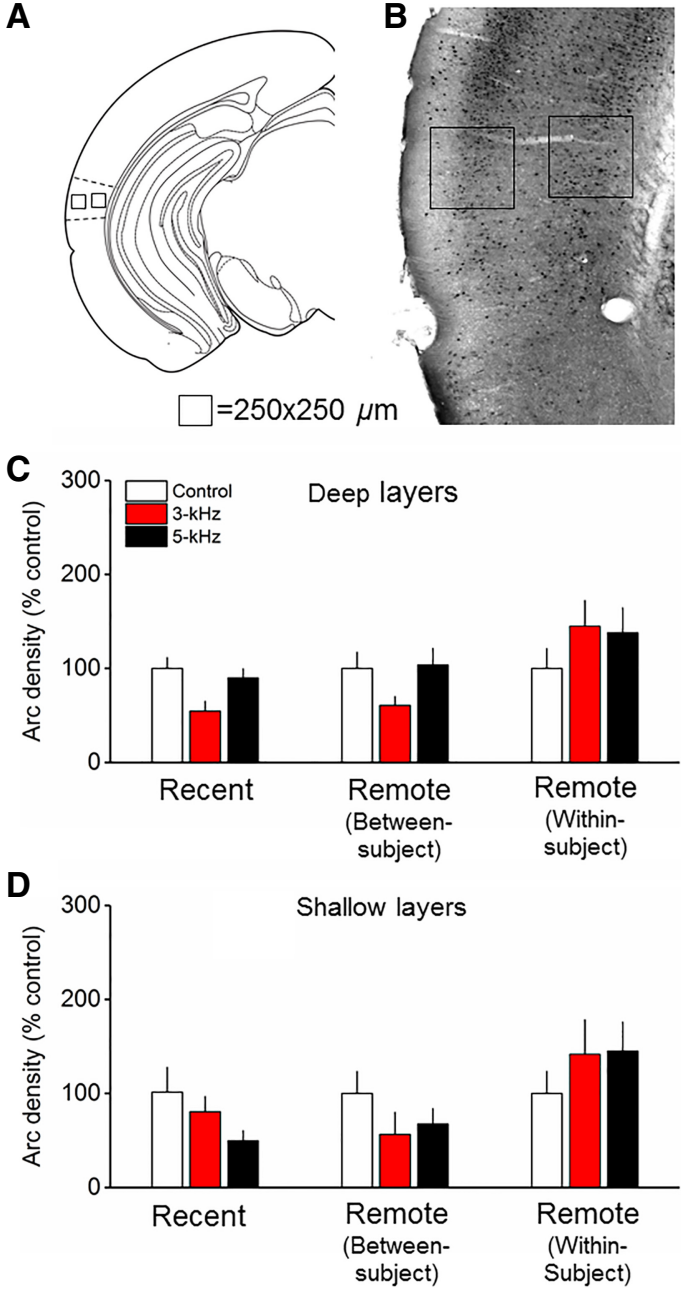

Figure 5. Arc expression following cued fear memory retrieval at recent and remote time points in the temporal association cortex (TeA). (A) Atlas image depicting the relative location of the counting frames in the TeA. The counting frame was positioned in shallow (centered $\sim 200 \mu \mathrm{m}$ from lateral edge) and deep layers (centered $\sim 500 \mu \mathrm{m}$ from lateral edge). (B) Representative micrograph depicting Arc immunohistochemistry and counting frame $\left(250 \mu \mathrm{m}^{2}\right)$. $(C, D)$ There were no effects of $\mathrm{kHz}$ on Arc expression in TeA deep or shallow layers. $n=7-8 /$ group, bars are mean \pm SEM.

discrimination (Chavez et al. 2009; Likhtik et al. 2014; Ghosh and Chattarji 2015; Jones et al. 2015; Grosso et al. 2018). The $3-\mathrm{kHz}$ stimulus was highly similar, in terms of physical attributes (frequency), to the 5-kHz CS. It could be speculated that the LAd response range was sufficiently broad to trigger plasticity in re- sponse to the $3-\mathrm{kHz}$ tone stimulus at multiple time points following learning.

Cued fear memory generalization over time was also associated with decreased Arc expression in the AIP and IL (Figs. 2, 4). There are two interpretations for our results: First, synaptic plasticity in the AIP and IL may have degraded over time, resulting in a reduction in the number of Arc-expressing neurons after retrieval of the generalized remote cued fear memory. Another interpretation is that Arc expression in the AIP and IL was actively "suppressed" over time, via inhibitory signaling. The IL has consistently been linked with suppressing conditioned fear responses, especially after extinction (Vidal-Gonzalez et al. 2006), while the AIP has been associated with processing learned safety signals (conditioned inhibition of fear) (Foilb et al. 2016). This leads to a model whereby over time, progressively increased suppression of IL and AIP output disinhibits amygdala circuits leading to exaggerated (generalized) CRs to novel tone stimuli. At the onset, this model may seem counterintuitive since reductions in GABAergic signaling, using knockdown and pharmacologic strategies, has been most consistently linked with fear memory generalization (Shaban et al. 2006; Bergado-Acosta et al. 2008; Sangha et al. 2009; Lynch et al. 2017). However, photosilencing mPFC output was shown to increase fear generalization (Xu and Sudhof 2013). Microcircuit-level analyses localized to MPFC subregions will be required to delineate the precise contributions of changes in inhibitory signaling over time to the expression of generalized fear (Courtin et al. 2014).

\section{Cued fear memory discrimination and new learning}

There is some evidence to suggest that discrimination training sharpens generalization gradients (reduces generalization) (Mackintosh 1974). We used a variant of discrimination training in which mice were fear conditioned with a tone CS and the next day presented with a novel tone. After 30-d, the same tone was presented in a within-subject design to test whether discrimination training improves stimulus control over time. This approach enabled a direct comparison of a generalized and discriminate cued fear memory using an identical physical stimulus. Results revealed a resharpening of the generalization gradient at $30 \mathrm{~d}$ when mice were presented with a brief exposure to the novel stimulus 24-h following learning (Fig. 1). Why might discrimination improve over time in a within-subject design? One interpretation of this result is that the unreinforced presentation of a novel auditory stimulus in a novel environment is akin to discrimination training (Hanson 1959), which triggered updating of the preexisting memory trace (Debiec et al. 2006). Improved discrimination over time was associated with a robust increase in $\operatorname{Arc}$ expression in the PL, supporting evidence for new learning. An interesting aspect of these data is that Arc expression in the PL was not increased following the first presentation of the $3-\mathrm{kHz}$ stimulus. Instead, 30-d after the initial presentation, there was an increase in Arc-positive cells in the PL that were associated with the accurate (discriminant)

Table 1. Cortico-amygdala patterns of Arc expression over time under conditions of generalization and discrimination

\begin{tabular}{|c|c|c|c|c|c|c|c|}
\hline & & PL & IL & AIP & LAd & TeA (deep) & TeA (shallow) \\
\hline \multirow[t]{2}{*}{ Recent } & 3-kHz discrimination & $97.4 \pm 11.1$ & $91.1 \pm 24.5$ & $98.9 \pm 31.5$ & $134.3 \pm 21.9^{*}$ & $54.7 \pm 10.3$ & $80.6 \pm 16.0$ \\
\hline & 5-kHz target & $158.0 \pm 12.3^{*}$ & $160.1 \pm 26.7$ & $55.2 \pm 11.3$ & $196.5 \pm 28.1^{*}$ & $89.9 \pm 9.6$ & $49.6 \pm 10.6$ \\
\hline \multirow{2}{*}{ Remote BS } & 3-kHz generalization & $88.2 \pm 13.1$ & $55.9 \pm 5.1^{\star *}$ & $10.4 \pm 4.8^{* \star *}$ & $128.6 \pm 18.6^{*}$ & $60.8 \pm 9.2$ & $56.4 \pm 23.5$ \\
\hline & $5-\mathrm{kHz}$ target & $117.1 \pm 16.1$ & $81.9 \pm 10.3$ & $21.3 \pm 9.1^{* * *}$ & $174.5 \pm 32.5^{*}$ & $103.7 \pm 17.6$ & $67.4 \pm 16.3$ \\
\hline \multirow[t]{2}{*}{ Remote WS } & 3-kHz discrimination & $235.6 \pm 33.2$ & $78.5 \pm 20.1$ & $174.1 \pm 56.2$ & $216.9 \pm 31.2^{*}$ & $144.9 \pm 27.2$ & $141.8 \pm 36.5$ \\
\hline & 5-kHz target & $159.6 \pm 29.5^{*}$ & $34.9 \pm 9.3$ & $62.8 \pm 24.1$ & $172.9 \pm 23.0^{* *}$ & $137.9 \pm 26.4$ & $144.9 \pm 30.9$ \\
\hline
\end{tabular}

Each cell contains normalized group means \pm SEM of Arc expression (see Materials and Methods). $\left(^{*}\right) P<0.05,\left({ }^{*}\right) P<0.01,\left({ }^{\star * *}\right) P<0.001$ compared with the control. 
retrieval of the $3-\mathrm{kHz}$ stimulus. These findings suggest that memory updating at early time points following learning triggered consolidation processes in response to the nontarget stimulus at protracted time frames following learning (Kwapis et al. 2017). Overall, these data support a role for PL functionality in fear memory discrimination (Xu and Sudhof 2013; Likhtik et al. 2014; Vieira et al. 2014; Spalding 2018).

\section{Neuronal correlates of fear memory stability over time}

The magnitude of the cued freezing response remained remarkably stable over at least 30-d, in both within- and between-subject designs, a finding consistent with previous work in rats (McAllister and McAllister 1963; Houston et al. 1999; Poulos et al. 2009) and mice (Balogh et al. 2002; Balogh and Wehner 2003). However, in both the within- and between-subject designs there was a small, albeit nonsignificant, increase in CS-elicited freezing over time (15\% and $9 \%$ increase, respectively), suggesting a degree of fear incubation (Pickens et al. 2013). This observation therefore does not rule out the possibility that at least some portion of the observed increases in generalized cued freezing responses over time in the between-subject design may have resulted from incubation processes. Indeed, both context (Poulos et al. 2016) and cued (Pickens et al. 2009) fear memory has been shown to incubate with the passage of time. Retrieval of the cued fear memory 1-d following learning was associated with increased Arc expression in the LAd, a finding consistent with previous work (Maddox and Schafe 2011). Over time, cued fear memory retrieval was associated with a refined (12\% decrease), but cued fear memory retrieval-specific (87.5\% increase/control), population of Arc-positive cells in the LAd. These data suggests that synapses in the LAd remain engaged and plastic in response to the CS even at a remote time frame following learning, a finding supported by BLA lesion (Maren et al. 1996; Poulos et al. 2009), IEG expression in the LAd (Kwon et al. 2012) and human fMRI data (Ritchey et al. 2008). It remains an open question whether presentation of the CS at the remote time point reactivated the same neuronal ensemble that was formed in the LAd during acquisition (Reijmers et al. 2007; Bergstrom et al. 2013a). There are however conflicting findings regarding the role for the amygdala in remote cued fear memory retrieval. Do-Monte et al. (2015) reported a reduction in activity ( $c$-fos) in the basolateral nucleus of the amygdala at 7-d following cued fear learning in rats (Do-Monte et al. 2015). It is possible that temporal fluctuations in the expression of retrieval-induced plasticity-related genes continue at more remote time points (i.e., duration longer than 24-h) following learning. It is also possible that the basal and lateral nuclei of the amygdala exhibit differential patterns of retrieval-induced plasticity over time (Bergstrom et al. 2013b). Finally, different molecular markers of neuronal activity may indicate different learning stages and processes.

The results fail to support a role for higher-order auditory cortex (TeA) plasticity in auditory cued fear memory retrieval over time. Although there was a change in Arc expression in the TeA over time (in both shallow and deep layers), the pattern of expression did not differ among experimental conditions (Fig. 5). This finding is at odds with several converging studies implicating the TeA in the retrieval of remote, but not recent, auditory cued fear memory retrieval (Sacco and Sacchetti 2010; Kwon et al. 2012; Grosso et al. 2015). The discrepancy in results may stem from differences in the category of activity-dependent molecular marker used (Arc/arg3.1 versus Zif268) or species-dependent differences (rat versus mouse).

Our findings support a role for the PL in cued fear memory expression (Fig. 2; Courtin et al. 2013). However, a previous study using $c$-fos showed increased activation in the PL at 7-d following cued fear learning (Do-Monte et al. 2015). It is possible that in- creased Arc expression related to context generalization may have occluded the detection of CS-elicited Arc expression in the PL (Stern et al. 2013; Vanvossen et al. 2017). It is also possible that the temporal dynamics in consolidation processes extend beyond 7-d after testing.

\section{What is the relationship between conditioned contextual and cued defensive freezing?}

The C57BL/6J mouse exhibits a robust contextual fear memory generalization phenotype (Balogh et al. 2002; Laxmi et al. 2003; Huckleberry et al. 2016), that increases over time (Wiltgen and Silva 2007; Cullen et al. 2015; Poulos et al. 2016). Here, we show generalization to a novel context 1-d following learning, using a C57BL/6 substrain (C57BL/6N). Over time, in both withinand between-subject design, generalization increased $(69.0 \%)$ (Supplemental Fig. S2). This result raises a critical question: to what degree might contextual fear memory generalization contribute to cued fear memory generalization? There are several proposed approaches as to how to account for, or normalize, baseline contextual fear in cued fear conditioning paradigms (Jacobs et al. 2010; Tipps et al. 2014). Here, we addressed this question by statistically comparing the amount of freezing during the CS with the amount of freezing during the equivalent time frame $(20-\mathrm{sec})$ immediately preceding the CS (Annau and Kamin 1961). We found that CS-elicited freezing was significantly elevated above baseline at the remote time point (Fig. 1). Based on these results, the conclusion is that B6 mice exhibit a remote cued fear memory generalization phenotype that can be isolated, at least in part, from generalized contextual fear.

\section{What is the nature of fear memory generalization over time?}

Memory generalization over time has been conceptualized as a form of "forgetting" in which conditioned responding increases to novel stimuli (Riccio et al. 1992; Jasnow et al. 2016). Increases in responding to novel stimuli can be graphically depicted in a "flattening" of a generalization gradient. Here, we demonstrate a flattening of the cued fear memory generalization gradient over time (Fig. 1), indicating that cued fear memory performance is fluid with the passage of time. A proposed mechanism of forgetting (generalization) is that it involves an active degradation, or change, in retrieval mechanics. Degradation of the cued fear memory trace itself is an unlikely interpretation, however, since novel stimuli evoked a significant degree of conditioned responding. The strength of responding to the CS also remained intact over time, suggesting a high degree of stability for the original CS-US association. Rather, a degradative process was more likely confined to a stimulus attribute (i.e., the tone frequency) which resulted in a broader, or coarser, representation of the CS and the expression of generalization (Hardt and Nadel 2017). This explanation is supported by results from a blocking study showing that fear memory for the frequency of the CS changes over time (Thomas and Riccio 1979).

\section{Overgeneralization and PTSD}

One area in which generalization may have special relevance is memory about dangerous things and places. In an environment in which cues may ambiguously signal the occurrence of threat, a false alarm (generalization) may confer a significant adaptive advantage over a miss (Dunsmoor and Paz 2015). However, overgeneralization of traumatic fear is maladaptive and represents a primary target for the treatment of PTSD and anxiety-related disorders (Lissek 2012; Morey et al. 2015; Kaczkurkin et al. 2016; Lopresto et al. 2016). Indeed, there are now several mouse and 
rat models (Siegmund and Wotjak 2007; McGuire et al. 2013; Coyner et al. 2014; Castro-Gomes et al. 2016; Sillivan et al. 2017) that exhibit fear overgeneralization phenotypes. The preclinical study of auditory cued fear memory generalization in particular may aid our understanding of trauma-related phenotypes, especially in populations with combat-acquired trauma, as traumatic fear memories likely contain a combination of discrete cued (foreground) and contextual (background) elements (Norrholm et al. 2014).

\section{Conclusions}

We report a time-dependent increase in cued fear memory generalization that was associated with a stable population of Arc-expressing neurons in the LAd and a temporally dynamic population of Arc-expressing neurons in the cortex. Over time, fear memory discrimination and new learning was associated with increased Arc expression in the PL cortex while generalization was associated with decreased Arc expression in the AIP and IL cortex. These data suggest that over time, neurons in the PL are more responsive after fear memory discrimination learning and are suppressed in the AIP and IL during generalization, which supports evidence that the PL and IL play distinct, and potentially opposing, roles in remote fear memory expression (Peters et al. 2009; Gourley and Taylor 2016). These data identify the dorsolateral amygdala, medial prefrontal, and insular cortices as key loci for synaptic plasticity underlying remote cued fear memory generalization.

\section{Materials and Methods}

\section{Animals}

Adult male C57BL/6N (B6N) mice were bred in-house (breeding stock derived from Charles River). Mice were group housed (2-4/ cage) on a 12-h LD cycle (lights on at 0600) with unrestricted access to food and water in a temperature $\left(21.1^{\circ} \mathrm{C}\right)$ and humidity $(65 \%)$ controlled vivarium. Mice were $85.42 \pm 13 \mathrm{~d}$ of age and weighed $28.8 \pm 3 \mathrm{~g}$ at the beginning of training. All procedures were conducted in accordance with the National Institutes of Health Guide for Care and Use of Laboratory Animals and were approved by the Vassar College Institutional Animal Care and Use Committee (IACUC). Disclosure for housing and husbandry procedures followed guidelines for transparent reporting in the field of behavioral neuroscience (Prager et al. 2011).

\section{Fear conditioning}

The fear conditioning chambers were housed in sound-attenuating cabinets (Coulbourn Instruments). All stimuli were administered via sound and shock generators that were controlled using Graphic State software (Coulbourn Instruments). All behavioral testing was conducted between 0800-1800 (light phase). On each testing day, the tone intensity (decibel; $\mathrm{dB}$ ) for each frequency of tone administered was measured in each chamber using a sound level meter (R8050, REED Instruments) and calibrated if necessary to verify that the $\mathrm{dB}$ was accurate and equivalent across chambers. Background $\mathrm{dB}=67$ across chambers. Mice were transferred to an adjacent holding room $30 \mathrm{~m}$ prior to training. For training, mice were placed into an unmodified fear conditioning chamber. Following $180 \mathrm{sec}$ of habituation, mice were presented with three tone stimuli $(75 \mathrm{~dB}, 5-\mathrm{kHz}, 20-\mathrm{sec})$ (i.e., the target conditioned stimulus; CS) that each coterminated with a foot shock unconditioned stimulus (US; 0.5 -sec, $0.6 \mathrm{~mA}$ ). Mice were removed from the chamber 60 -sec after the final stimulus presentation and returned to the colony room. The inter-trial interval (ITI) duration was randomized (20- and $80-\mathrm{sec}$ ). On testing days, mice were transferred from the vivarium to a different holding room in different holding cages and carts. All retrieval tests were conducted in the same room as conditioning but distinguished by altering the lighting and background noise using a fan. The testing chamber was al- tered to mask it from the training chamber. The testing chamber was distinguished from the training chamber using a white Plexiglas floor covered with clean bedding, an additional cue light, black and white side panels, and a novel odorant (1\% acetic acid).

\section{Experiment 1: between-subject}

One day following fear conditioning, mice in the "Recent" group were randomly assigned to tone stimuli frequency experimental groups (2-, 3-, 5-, 8-, or 12-kHz) and allowed to explore the testing chamber freely for $180 \mathrm{sec}$ prior to the presentation of a tone stimulus $(75 \mathrm{~dB}, 20-\mathrm{sec})$ at either $2-, 3-, 5-, 8-$, or $12-\mathrm{kHz}$ frequencies. Mice were removed from the chamber $60 \mathrm{sec}$ after the final stimulus presentation and returned to the colony room (400-sec total test time; ITIs 80- and 20-sec).

Thirty days following fear conditioning, mice in the "Remote" group were placed into testing chamber for 400 -sec, but received no tone stimuli. We included an additional exposure to the chamber at the recent time point to equate the duration of contextual exposure across between- and within-subject designs (see below). Thirty days later mice were randomly designated to tone stimuli frequency experimental groups $(2-, 3-, 5-, 8-$, or $12-\mathrm{kHz}$ ) and allowed to explore the testing chamber freely for $180 \mathrm{sec}$ prior to the presentation of a tone stimulus $(75 \mathrm{~dB}$, $20-\mathrm{sec}$ ) at either 2-, 3-, 5-, 8-, or 12-kHz frequencies. Mice were removed from the chamber 60 -sec after the final stimulus presentation and returned to the colony room (400-sec total test time). The ITI duration was different from training (80- and 20-sec). Group sizes for the Recent group were $2-\mathrm{kHz}(n=13), 3-\mathrm{kHz}(n=$ $16), 5-\mathrm{kHz}(n=22), 8-\mathrm{kHz}(n=11), 12-\mathrm{kHz}(n=11)$. Group sizes for the Remote group were $2-\mathrm{kHz}(n=10), 3-\mathrm{kHz}(n=15), 5-\mathrm{kHz}$ $(n=14), 8-\mathrm{kHz}(n=11), 12-\mathrm{kHz}(n=9)$. For the behavioral analysis, all mice, including those allocated to Arc immunohistochemistry (see below), were included.

\section{Experiment 2: within-subject}

One day following fear conditioning, mice in the "Recent" group were randomly assigned to tone stimuli frequency experimental groups (2-, 3-, 5-, 8-, or 12-kHz) and allowed to explore the testing chamber freely for 180 -sec prior to the presentation of a tone stimulus $(75 \mathrm{~dB}, 20-\mathrm{sec})$ at either $2-, 3-, 5-, 8-$, or $12-\mathrm{kHz}$ frequencies. Mice were removed from the chamber $60 \mathrm{sec}$ after the final stimulus presentation and returned to the colony room (400-sec total test time; ITIs 80 - and 20-sec).

Thirty days following "Recent" memory reactivation, mice in the "Remote" group were placed back into testing chamber and allowed to explore the context freely for 180 -sec before receiving the same tone stimulus with same ITIs at the same frequency (2-, 3-, 5-, $8-$, or $12-\mathrm{kHz})$ and strength $(75 \mathrm{~dB}, 20-\mathrm{sec})$ as they had received 30 -d prior. Group sizes were $2-\mathrm{kHz}(n=11), 3-\mathrm{kHz}(n=10), 5-\mathrm{kHz}$ $(n=10), 8-\mathrm{kHz}(n=10), 12-\mathrm{kHz}(n=11)$.

\section{Experiment 3: between-subject (no context preexposure)}

To assess how preexposure to the testing chamber might influence remote CS generalization, we included an experimental group that was not exposed to the testing chamber at the recent time point. We chose the 2- and 3-kHz frequency groups as comparison groups with the $5-\mathrm{kHz}$ group because they showed the greatest degree of generalization in the between-subject design. Thirty days following training (using an identical training protocol as outlined above), mice were placed into the testing chamber for 180 -sec before being presented with three tone stimuli $(75 \mathrm{~dB}, 20-\mathrm{sec})$ at either 2-, 3-, or 5-kHz frequencies. Mice were removed from the chamber 60 -sec after the final stimulus presentation and returned to the colony room (400-sec total test time). Group sizes were $2-\mathrm{kHz}(n=6), 3 \mathrm{kHz}(n=6), 5-\mathrm{kHz}(n=6)$.

\section{Behavioral analysis}

All experimenters were blind to the experimental conditions. Immobility ("freezing") was used as a behavioral measure of a 
conditioned defensive reaction ("fear") (Fanselow 1980). Freezing was operationally defined as complete immobility, except for respiration. Freezing behavior was analyzed from prerecorded digitized videos using SMART video tracking software (PanLab Harvard Apparatus) and a subset of videos were verified for freezing behavior using hand-scoring by a trained human rater. Results revealed a remarkably high inter-rater reliability (SMART versus hand-scoring; $R^{2}=0.99$ ). For the CS test, freezing was measured for the 180 -sec habituation period and during the three CS (20-sec) presentations. A mean freezing value was calculated across all CS presentations and transformed into a percentage of total time during the CS or habituation period (freezing percentage). A discrimination index was used to quantify fear memory generalization $(\mathrm{Xu}$ and Sudhof 2013). The discrimination index was generated by dividing the mean of the target stimulus ( $\mathrm{T}$ ) by the sum of $\mathrm{T}$ and the nontarget $(\mathrm{N})$ stimulus $[\mathrm{T} /(\mathrm{T}+\mathrm{N})]$. In a discrimination index, a value of 1 indicates discrimination and a value of 0.5 indicates generalization. To address the question of how contextual freezing relates to cued freezing, we measured the freezing response immediately prior to the presentation of the CS for an equivalent amount of time as the CS $(20-\mathrm{sec})$. The Pre-CS and CS freezing levels (freezing percentage) were averaged across the three CS presentations.

\section{Immunohistochemistry}

For Arc immunostaining, mice were perfused exactly 60-min following the CS retrieval test. The 60-min time point was chosen based on previous studies using for Arc IHC for functional imaging (Vazdarjanova et al. 2006; Lonergan et al. 2010; Chia and Otto 2013). Three "no tone" control groups that corresponded with each timepoint (Recent, Remote within-subject, Remote betweensubject) were included in the Arc IHC experiment. The control groups were designed to provide a measure of Arc expression related to background conditioning (contextual-associated fear). All control groups underwent fear conditioning using identical methods described above for the experimental groups. For the recent group, control mice were placed into the testing chamber for 400-sec 1-d following fear conditioning, but received no tone stimuli. In the within-subject design, all mice received the $5-\mathrm{kHz}$ target CS in the testing chamber at the recent time point (1-d) and were placed again into testing chamber for 400 -sec at the remote time point (30-d), but received no tone stimuli. In the between-subject design, mice were placed into the testing chamber for 400 -sec at the recent (1-d) and remote time point $(30-\mathrm{d})$, but received no tone stimuli.

Mice were anesthetized with an intraperitoneal (i.p.) injection of a ketamine/xylazine $(100 / 10 \mathrm{mg} / \mathrm{kg})$ cocktail and transcardially perfused with ice-cold $1 \times$ phosphate buffered saline (PBS; $\mathrm{pH} 7.4$ ) followed by ice-cold $4 \%$ paraformaldehyde $/ 0.1 \mathrm{M}$ phosphate buffer $(\mathrm{PB})$ at $\mathrm{pH}$ 7.4. Brains were removed and stored in the fixative overnight $\left(4^{\circ} \mathrm{C}\right)$ then stored no longer than 7 -d in PBS. Free floating serial coronal brain sections of the forebrain were sliced on a vibratome (VT1200, Leica Biosystems Inc.) at $40 \mu \mathrm{m}$. Every other section was processed for Arc/arg 3.1 immunoreactivity. For IHC, sections were incubated at room temperature on an orbital shaker at low speed.

Sections were first rinsed in PBS. Then the tissue was blocked in $1 \%$ bovine serum albumin (BSA)/0.02\% Triton X-100/1× PBS for $30-\mathrm{m}$. Next, sections were incubated in a 1:100 dilution of a monoclonal Arc anti-mouse primary antibody (C-7, sc-17838, Santa Cruz Biotechnology) in 1\% BSA/0.02\% Triton X-100/1× PBS for 24-h at room temperature. Sections were then rinsed in PBS prior to incubation with an anti-mouse biotinylated IgG (1:200; Vector Laboratories) in 1\% BSA/.0.02\% Triton X-100/1x PBS. After washes in PBS, the sections were incubated in avidinbiotinylated horseradish peroxidase for 1-h (ABC-elite; Vector Laboratories). Then, sections were rinsed in PBS and activated neurons were developed in 1,3- diaminobenzidine (DAB) peroxidase substrate with nickel for exactly $3-\mathrm{m}$. After a final wash in PBS, serial sections were mounted on gel-coated slides, air-dried, then dehydrated in a graded series of alcohol $(50 \%, 70 \%, 95 \%$, and $100 \%)$, followed by xylenes, and cover-slipped (1.5 $\mathrm{mm}$ thick- ness) with DPX mounting medium (Sigma-Aldrich) for bright field microscopy. Importantly, immunohistochemistry staining was counterbalanced across all experimental conditions $(\mathrm{kHz}$ and Time) to eliminate possible bias across groups due to inconsistencies in the experimental procedures and histological processing.

\section{Arc expression analysis}

For all Arc-positive neuronal counting the experimenter was blind to the experimental conditions. For each brain region, cell counts were conducted in six hemispheres (left and right) per mouse. Counting was conducted on nonconsecutive sections to avoid double-counting. Neurolucida and NeuroExplorer software (MBF Bioscience) were used to manually count and quantify Arc-positive cells. All counting was conducted using bright-field microscopy (Axioplane, Ziess) and a $250 \mu^{2}$ counting frame. Each brain region was first identified under a $2.5 \times$ objective and the counting frame positioned over the region of interest (ROI). Importantly, the counting frame was positioned at a consistent ROI location across sections using anatomical landmarks (see below) in conjunction with a mouse brain atlas (Paxinos and Franklin 2004). The sections chosen for counting were spaced evenly and effort was made to not include the rostral- and caudal-most regions to avoid sampling outside the ROI. All Arc-positive cell counting was conducted under a $20 \times / 0.5$ NA objective $(200 \times$ final magnification) with Koehler illumination principles applied. Arc-positive cell counting was conducted in the LAd, PL, IL, AIP, and TeA. To locate the TeA, the relative location of the rhinal fissure was used as an anatomical landmark. The center-point of the counting frame was consistently positioned $150-200 \mu \mathrm{m}$ (shallow layers) and 550-600 $\mu \mathrm{m}$ (deep layers) from the lateral surface of the cortex and in slices between rostrocaudal levels bregma -2.2 and -3.2 $\mathrm{mm}$. This represented the rostral portion of the TeA. We counted from both deep and shallow layers as there is evidence for layerspecificity for remote cued fear memory storage in the TeA (Grosso et al. 2016). To locate the LAd, we used various amygdalacentric anatomical landmarks, including the rhinal fissure, central amygdala and external capsule. Arc-positive cells in the LAd were counted from slices between rostrocaudal levels bregma -1.7 and $-2.2 \mathrm{~mm}$. To locate the PL, the forceps minor of the corpus callosum was used as an anatomical landmark. The counting frame was consistently positioned $\sim 550-600 \mu \mathrm{m}$ (deep layers) from midline (PL) based on evidence suggesting deeper layers (V-VI) are more excitable than shallow layers (Song and Moyer 2018). Arc-positive cells in the PL were counted between rostrocaudal levels of bregma 2.0 and 1.5. To locate the IL, we used the broadening shallow layers (II/III) ventral to the PL as an anatomical landmark (Giustino and Maren 2015). The counting frame was consistently positioned $\sim 150-200 \mu \mathrm{m}$ from midline (shallow layers). We chose the IL shallow layers for sampling because the cells were more readily visible under our Arc IHC preparation. Further, the shallow layers of the IL have been shown to be more excitable than PL shallow layers (although less excitable overall than deep layers) (Song and Moyer 2018). Arc-positive cells in the IL were counted between rostrocaudal levels of bregma 1.9 and 1.5. To locate the AIP, various anatomical landmarks including the position of the claustrum (high density of staining in this region), the external capsule, and bifurcation of the external capsule at the LAd were used. The counting frame was consistently positioned $\sim 150-200 \mu \mathrm{m}$ from the lateral surface of the cortex (shallow layers). We chose AIP shallow layers for sampling to avoid miss-sampling Arc-positive neurons in the claustrum (positioned medial to the AIP). Arc-positive cells in the AIP were counted between rostrocaudal levels of bregma -0.3 and -0.9. Arc neuronal density (cells $/ 250 \mu \mathrm{m}^{2}$ ) was expressed as either raw density values or was normalized to the group mean of the corresponding control group. The normalized values were expressed as a percentage and averaged across mice for group means. Normalization allowed for the isolation of changes in Arc expression associated with the retrieval of auditory cued fear memory from neuronal activation related to background conditioning (contextual associated fear) and the testing environment. 


\section{Statistical analysis}

\section{Behavior}

For the behavioral analysis, the dependent variable was either the discrimination index or freezing percentage. The independent variables were the frequency $(\mathrm{kHz})$ of the CS $(2-, 3-, 5-, 8-, 12-\mathrm{kHz})$ and the time point (Time) of memory retrieval (Recent, Remote within-subject, Remote between-subject). In the within-subject design, a repeated-measures analysis of variance (ANOVA) with the between-subject factor $(\mathrm{kHz})$ and within-subject factor (Time) were compared. All data were first checked for sphericity using Machly's test and the degrees of freedom corrected (GreenhouseGeisser correction) if warranted. Significant interactions were followed up by Bonferroni corrected independent samples $t$-tests $(\mathrm{kHz})$ or paired $t$-tests (Time). In the between-subject design, a univariate ANOVA with the factors $(\mathrm{kHz} \times$ Time) was used to compare freezing levels. All data were first checked for normality using Levene's test and corrected if warranted. Significant interactions were followed-up with a Scheffe post-hoc test. To reduce the overall number of mice used in these experiments a common "Recent" group was used in all analysis.

\section{Pattern analysis of cortico-amygdala Arc expression}

A multivariate analysis of variance (MANOVA) was used to test the statistical relationship among the normalized Arc expression levels in LA, PL, IL, TeA, and AIP at different $\mathrm{kHz}$ frequencies (control, 3-, $5-\mathrm{kHz}$ ) and Time points (Recent, Remote-BS, Remote-WS) following learning. A significant value for the conservative Pillai's Trace test statistic was followed up by ANOVA. Assumptions of multivariate normality and equality of covariance matrices were checked using Levene's test and Box's test, respectively. Violation of Levene's test was followed up with a Welsch test and if significant, post-hoc testing (Scheffe's test). Next, functional discriminant analyses (DA) was applied to the data set to determine how the pattern of Arc expression in the LA, PL, IL, TeA, and AIP segregates either $\mathrm{kHz}$ frequency or retrieval time point groups. DA is a classification method that finds an optimal combination of variables (a dimension) that discriminates the groups. For DA, the grouping variable was the experimental condition $(\mathrm{kHz})$ and the independent variables (discriminate variates) were the normalized Arc expression values across all cortico-amygdala regions (LA, PL, IL, TeA, and AIP) analyzed at each time point. The result of DA is a set of canonical variate correlation coefficients (loading values) in a structure matrix that represents the relative contribution or "meaningfulness" of each variable (Arc expression in each brain region) to the separation of the groups $(\mathrm{kHz})$. Variables with correlations greater or less than 0.3 were reported and interpreted. In this way, DA was used to determine how relative patterns of Arc expression across a corticoamygdala circuit contribute to group separation (Control, 3-, or $5-\mathrm{kHz}$ ). We also statistically compared the variate scores associated with each significant discriminant function. The variate scores represent the "relatedness" or "strength" of a dimension (pattern of Arc expression across the cortico-amygdala circuit) to an individual. We grouped scores by condition (5-, 3-kHz, or Control) and statistically compared them (ANOVA). All data for DA were log transformed and missing values ( $<4 \%$ of total) estimated using unbiased multiple imputation. For all statistics, significance was set at $P \leq 0.05$. All data are represented as the mean \pm the standard error of the mean (SEM). All group sizes can also be found in the figure captions.

\section{Acknowledgments}

The authors are grateful to Charles Pickens and Andrew Poulos for comments on a previous version of the manuscript. The authors thank Anya Scott-Wallace for technical assistance. Research supported by Vassar College Start-up Operating Funds and the Vassar College Undergraduate Research Summer Institute (URSI).

\section{References}

Annau Z, Kamin LJ. 1961. The conditioned emotional response as a function of intensity of the US. J Comp Physiol Psychol 54: 428.
Armony JL, Servan-Schreiber D, Romanski LM, Cohen JD, LeDoux JE. 1997. Stimulus generalization of fear responses: effects of auditory cortex lesions in a computational model and in rats. Cereb Cortex 7: 157-165.

Balogh SA, Wehner JM. 2003. Inbred mouse strain differences in the establishment of long-term fear memory. Behav Brain Res 140: 97-106.

Balogh SA, Radcliffe RA, Logue SF, Wehner JM. 2002. Contextual and cued fear conditioning in C57BL/6J and DBA/2J mice: context discrimination and the effects of retention interval. Behav Neurosci 116: 947.

Bergado-Acosta JR, Sangha S, Narayanan RT, Obata K, Pape HC, Stork O. 2008. Critical role of the $65-\mathrm{kDa}$ isoform of glutamic acid decarboxylase in consolidation and generalization of Pavlovian fear memory. Learn Mem 15: 163-171.

Bergstrom HC. 2016. The neurocircuitry of remote cued fear memory. Neurosci Biobehav Rev 71: 409-417.

Bergstrom HC, McDonald CG, Dey S, Fernandez GM, Johnson LR. 2013a. Neurons activated during fear memory consolidation and reconsolidation are mapped to a common and new topography in the lateral amygdala. Brain Topogr 26: 468-478.

Bergstrom HC, McDonald CG, Dey S, Tang H, Selwyn RG, Johnson LR. 2013b. The structure of Pavlovian fear conditioning in the amygdala. Brain Struct Funct 218: 1569-1589.

Bouton ME, Nelson JB, Rosas JM. 1999. Stimulus generalization, context change, and forgetting. Psychol Bull 125: 171

Cambiaghi M, Grosso A, Likhtik E, Mazziotti R, Concina G, Renna A, Sacco T, Gordon JA, Sacchetti B. 2016. Higher-order sensory cortex drives basolateral amygdala activity during the recall of remote, but not recently learned fearful memories. J Neurosci 36: 1647-1659.

Castro-Gomes V, Bergstrom HC, McGuire JL, Parker CC, Coyner J, Landeira-Fernandez J, Ursano RJ, Palmer AA, Johnson LR. 2016. A dendritic organization of lateral amygdala neurons in fear susceptible and resistant mice. Neurobiol Learn Mem 127: 64-71.

Chavez CM, McGaugh JL, Weinberger NM. 2009. The basolateral amygdala modulates specific sensory memory representations in the cerebral cortex. Neurobiol Learn Mem 91: 382-392.

Chia C, Otto T. 2013. Hippocampal arc (Arg3. 1) expression is induced by memory recall and required for memory reconsolidation in trace fear conditioning. Neurobiol Learn Mem 106: 48-55.

Cho JH, Huang BS, Gray JM. 2016. RNA sequencing from neural ensembles activated during fear conditioning in the mouse temporal association cortex. Sci Rep 6: 31753 .

Courtin J, Bienvenu T, Einarsson E, Herry C. 2013. Medial prefrontal cortex neuronal circuits in fear behavior. Neuroscience 240: 219-242.

Courtin J, Chaudun F, Rozeske RR, Karalis N, Gonzalez-Campo C, Wurtz H, Abdi A, Baufreton J, Bienvenu TC, Herry C. 2014. Prefrontal parvalbumin interneurons shape neuronal activity to drive fear expression. Nature 505: 92-96.

Coyner J, McGuire JL, Parker CC, Ursano RJ, Palmer AA, Johnson LR. 2014. Mice selectively bred for high and low fear behavior show differences in the number of pMAPK (p44/42 ERK) expressing neurons in lateral amygdala following Pavlovian fear conditioning. Neurobiol Learn Mem 112: $195-203$.

Cullen PK, Gilman TL, Winiecki P, Riccio DC, Jasnow AM. 2015. Activity of the anterior cingulate cortex and ventral hippocampus underlie increases in contextual fear generalization. Neurobiol Learn Mem 124: 19-27.

Debiec J, Doyere V, Nader K, Ledoux JE. 2006. Directly reactivated, but not indirectly reactivated, memories undergo reconsolidation in the amygdala. Proc Natl Acad Sci 103: 3428-3433.

Do-Monte FH, Quinones-Laracuente K, Quirk GJ. 2015. A temporal shift in the circuits mediating retrieval of fear memory. Nature 519: 460-463.

Dunsmoor JE, Paz R. 2015. Fear generalization and anxiety: behavioral and neural mechanisms. Biol Psychiatry 78: 336-343.

Fanselow MS. 1980. Conditional and unconditional components of post-shock freezing. Pavlov J Biol Sci 15: 177-182.

Fitzgerald P, Pinard C, Camp M, Feyder M, Sah A, Bergstrom H, Graybeal C, Liu Y, Schlüter O, Grant S. 2014. Durable fear memories require PSD-95. Mol Psychiatry 20: $901-912$.

Foilb AR, Flyer-Adams JG, Maier SF, Christianson JP. 2016. Posterior insular cortex is necessary for conditioned inhibition of fear. Neurobiol Learn Mem 134: 317-327.

Gale GD, Anagnostaras SG, Godsil BP, Mitchell S, Nozawa T, Sage JR, Wiltgen B, Fanselow MS. 2004. Role of the basolateral amygdala in the storage of fear memories across the adult lifetime of rats. J Neurosci 24: 3810-3815.

Ghosh S, Chattarji S. 2015. Neuronal encoding of the switch from specific to generalized fear. Nat Neurosci 18: 112-120.

Giustino TF, Maren S. 2015. The role of the medial prefrontal cortex in the conditioning and extinction of fear. Front Behav Neurosci 9: 298.

Gourley SL, Taylor JR. 2016. Going and stopping: dichotomies in behavioral control by the prefrontal cortex. Nat Neurosci 19: 656-664.

Gouty-Colomer LA, Hosseini B, Marcelo IM, Schreiber J, Slump DE, Yamaguchi S, Houweling AR, Jaarsma D, Elgersma Y, Kushner SA. 2015. 
Arc expression identifies the lateral amygdala fear memory trace. Mol Psychiatry 21: 364-375.

Grosso A, Cambiaghi M, Concina G, Sacco T, Sacchetti B. 2015. Auditory cortex involvement in emotional learning and memory. Neuroscience 299: $45-55$.

Grosso A, Cambiaghi M, Milano L, Renna A, Sacco T, Sacchetti B. 2016. Region-and layer-specific activation of the higher order auditory cortex Te2 after remote retrieval of fear or appetitive memories. Cereb Cortex 27: 3140-3151.

Grosso A, Santoni G, Manassero E, Renna A, Sacchetti B. 2018. A neuronal basis for fear discrimination in the lateral amygdala. Nat Commun 9: 1214.

Gruene T, Flick K, Rendall S, Cho JH, Gray J, Shansky R. 2016. Activity-dependent structural plasticity after aversive experiences in amygdala and auditory cortex pyramidal neurons. Neuroscience 328: 157-164.

Guttman N, Kalish HI. 1956. Discriminability and stimulus generalization. J Exp Psychol 51: 79.

Guzowski JF, Lyford GL, Stevenson GD, Houston FP, McGaugh JL, Worley PF, Barnes CA. 2000. Inhibition of activity-dependent arc protein expression in the rat hippocampus impairs the maintenance of long-term potentiation and the consolidation of long-term memory. J Neurosci 20: 3993-4001.

Hanson HM. 1959. Effects of discrimination training on stimulus generalization. J Exp Psychol 58: 321.

Hardt O, Nadel L. 2017. Systems consolidation revisited, but not revised: the promise and limits of optogenetics in the study of memory. Neurosci Lett. doi: 10.1016/j.neulet.2017.11.062.

Houston FP, Stevenson GD, McNaughton BL, Barnes CA. 1999. Effects of age on the generalization and incubation of memory in the F344 rat. Learn Mem 6: 111-119.

Huckleberry KA, Ferguson LB, Drew MR. 2016. Behavioral mechanisms of context fear generalization in mice. Learn Mem 23: 703-709.

Ito W, Pan BX, Yang C, Thakur S, Morozov A. 2009. Enhanced generalization of auditory conditioned fear in juvenile mice. Learn Mem 16: $187-192$.

Jacobs NS, Cushman JD, Fanselow MS. 2010. The accurate measurement of fear memory in Pavlovian conditioning: resolving the baseline issue. J Neurosci Methods 190: 235-239.

Jasnow AM, Cullen PK, Riccio DC. 2012. Remembering another aspect of forgetting. Front Psychol 3: 1.

Jasnow AM, Lynch JF III, Gilman TL, Riccio DC. 2016. Perspectives on fear generalization and its implications for emotional disorders. J Neurosci Res 95: 821-835.

Jones GL, Soden ME, Knakal CR, Lee H, Chung AS, Merriam EB, Zweifel LS. 2015. A genetic link between discriminative fear coding by the lateral amygdala, dopamine, and fear generalization. Elife 4: e08969.

Kaczkurkin AN, Burton PC, Chazin SM, Manbeck AB, Espensen-Sturges T, Cooper SE, Sponheim SR, Lissek S. 2016. Neural substrates of overgeneralized conditioned fear in PTSD. Am J Psychiatry 174: 125-134.

Kim WB, Cho J. 2017. Encoding of discriminative fear memory by input-specific LTP in the amygdala. Neuron 95: 1129-1146. e5.

Kwapis JL, Jarome TJ, Ferrara NC, Helmstetter FJ. 2017. Updating procedures can reorganize the neural circuit supporting a fear memory. Neuropsychopharmacology 42: 1688-1697.

Kwon JT, Jhang J, Kim HS, Lee S, Han JH. 2012. Brain region-specific activity patterns after recent or remote memory retrieval of auditory conditioned fear. Learn Mem 19: 487-494.

Laxmi TR, Stork O, Pape H. 2003. Generalisation of conditioned fear and its behavioural expression in mice. Behav Brain Res 145: 89-98.

Likhtik E, Stujenske JM, Topiwala MA, Harris AZ, Gordon JA. 2014. Prefrontal entrainment of amygdala activity signals safety in learned fear and innate anxiety. Nat Neurosci 17: 106-113.

Lissek S. 2012. Toward an account of clinical anxiety predicated on basic, neurally mapped mechanisms of Pavlovian fear-learning: the case for conditioned overgeneralization. Depress Anxiety 29: 257-263.

Lonergan ME, Gafford GM, Jarome TJ, Helmstetter FJ. 2010. Time-dependent expression of arc and zif 268 after acquisition of fear conditioning. Neural Plast 2010: 139891.

Lopresto D, Schipper P, Homberg JR. 2016. Neural circuits and mechanisms involved in fear generalization: implications for the pathophysiology and treatment of posttraumatic stress disorder. Neurosci Biobehav Rev 60: $31-42$.

Lyford GL, Yamagata K, Kaufmann WE, Barnes CA, Sanders LK, Copeland NG, Gilbert DJ, Jenkins NA, Lanahan AA, Worley PF. 1995. Arc, a growth factor and activity-regulated gene, encodes a novel cytoskeleton-associated protein that is enriched in neuronal dendrites. Neuron 14: 433-445.

Lynch JF, Winiecki P, Gilman TL, Adkins JM, Jasnow AM. 2017. Hippocampal GABAB (1a) receptors constrain generalized contextual fear. Neuropsychopharmacology 42: 914-924.
Mackintosh NJ. 1974. The psychology of animal learning. Academic Press, New York.

Maddox SA, Schafe GE. 2011. The activity-regulated cytoskeletal-associated protein $(\operatorname{arc} / \mathrm{Arg} 3.1)$ is required for reconsolidation of a Pavlovian fear memory. J Neurosci 31: 7073-7082.

Mamiya N, Fukushima H, Suzuki A, Matsuyama Z, Homma S, Frankland PW, Kida S. 2009. Brain region-specific gene expression activation required for reconsolidation and extinction of contextual fear memory. J Neurosci 29: 402-413.

Maren S, Aharonov G, Fanselow MS. 1996. Retrograde abolition of conditional fear after excitotoxic lesions in the basolateral amygdala of rats: absence of a temporal gradient. Behav Neurosci 110: 718 .

McAllister WR, McAllister DE. 1963. Increase over time in the stimulus generalization of acquired fear. J Exp Psychol 65: 576-582.

McGuire JL, Bergstrom HC, Parker CC, Le T, Morgan M, Tang H, Selwyn RG, Silva AC, Choi K, Ursano RJ, et al. 2013. Traits of fear resistance and susceptibility in an advanced intercross line. Eur J Neurosci 38: 3314-3324.

Morey R, Dunsmoor J, Haswell C, Brown V, Vora A, Weiner J, Stjepanovic D, Wagner H, Brancu M, Marx CE. 2015. Fear learning circuitry is biased toward generalization of fear associations in posttraumatic stress disorder. Transl Psychiatry 5: e700.

Morrison DJ, Rashid AJ, Yiu AP, Yan C, Frankland PW, Josselyn SA. 2016. Parvalbumin interneurons constrain the size of the lateral amygdala engram. Neurobiol Learn Mem 135: 91-99.

Nakayama D, Hashikawa-Yamasaki Y, Ikegaya Y, Matsuki N, Nomura H. 2016. Late arc/Arg3.1 expression in the basolateral amygdala is essential for persistence of newly-acquired and reactivated contextual fear memories. Sci Rep 6: 21007.

Norrholm SD, Jovanovic T, Briscione MA, Anderson KM, Kwon CK, Warren VT, Bosshardt L, Bradley B. 2014. Generalization of fear-potentiated startle in the presence of auditory cues: a parametric analysis. Front Behav Neurosci 8: 361.

Paxinos G, Franklin KB. 2004. The mouse brain in stereotaxic coordinates. Elsevier, Amsterdam.

Pearce JM. 1987. A model for stimulus generalization in Pavlovian conditioning. Psychol Rev 94: 61.

Perkins CC Jr, Weyant RG. 1958. The interval between training and test trials as a determiner of the slope of generalization gradients. J Comp Physiol Psychol 51: 596.

Peters J, Kalivas PW, Quirk GJ. 2009. Extinction circuits for fear and addiction overlap in prefrontal cortex. Learn Mem 16: 279-288.

Phillips R, LeDoux J. 1992. Differential contribution of amygdala and hippocampus to cued and contextual fear conditioning. Behav Neurosci 106: 274

Pickens CL, Golden SA, Adams-Deutsch T, Nair SG, Shaham Y. 2009. Long-lasting incubation of conditioned fear in rats. Biol Psychiatry 65: 881-886.

Pickens CL, Golden SA, Nair SG. 2013. Incubation of fear. Curr Protoc Neurosci Chapter 6: Unit 6.27.

Plath N, Ohana O, Dammermann B, Errington ML, Schmitz D, Gross C, Mao X, Engelsberg A, Mahlke C, Welzl H. 2006. Arc/Arg3. 1 is essential for the consolidation of synaptic plasticity and memories. Neuron 52: $437-444$.

Ploski JE, Pierre VJ, Smucny J, Park K, Monsey MS, Overeem KA, Schafe GE. 2008. The activity-regulated cytoskeletal-associated protein ( $\operatorname{arc} / \mathrm{Arg} 3.1)$ is required for memory consolidation of Pavlovian fear conditioning in the lateral amygdala. J Neurosci 28: 12383-12395.

Poulos AM, Li V, Sterlace SS, Tokushige F, Ponnusamy R, Fanselow MS. 2009. Persistence of fear memory across time requires the basolateral amygdala complex. Proc Natl Acad Sci 106: 11737-11741.

Poulos AM, Mehta N, Lu B, Amir D, Livingston B, Santarelli A, Zhuravka I, Fanselow MS. 2016. Conditioning- and time-dependent increases in context fear and generalization. Learn Mem 23: 379-385.

Prager EM, Bergstrom HC, Grunberg NE, Johnson LR. 2011. The importance of reporting housing and husbandry in rat research. Front Behav Neurosci 5: 38

Reijmers LG, Perkins BL, Matsuo N, Mayford M. 2007. Localization of a stable neural correlate of associative memory. Science 317: 1230-1233.

Riccio DC, Ackil JK, Burch-Vernon A. 1992. Forgetting of stimulus attributes: methodological implications for assessing associative phenomena. Psychol Bull 112: 433.

Richards BA, Frankland PW. 2017. The persistence and transience of memory. Neuron 94: 1071-1084.

Ritchey M, Dolcos F, Cabeza R. 2008. Role of amygdala connectivity in the persistence of emotional memories over time: an event-related fMRI investigation. Cereb Cortex 18: 2494-2504.

Sacco T, Sacchetti B. 2010. Role of secondary sensory cortices in emotional memory storage and retrieval in rats. Science 329: 649-656.

Sangha S, Narayanan RT, Bergado-Acosta JR, Stork O, Seidenbecher T, Pape HC. 2009. Deficiency of the $65 \mathrm{kDa}$ isoform of glutamic acid 
decarboxylase impairs extinction of cued but not contextual fear memory. J Neurosci 29: 15713-15720.

Shaban H, Humeau Y, Herry C, Cassasus G, Shigemoto R, Ciocchi S, Barbieri S, van der Putten H, Kaupmann K, Bettler B. 2006. Generalization of amygdala LTP and conditioned fear in the absence of presynaptic inhibition. Nat Neurosci 9: 1028-1035.

Shepard RN. 1987. Toward a universal law of generalization for psychological science. Science 237: 1317-1323.

Shepherd JD, Bear MF. 2011. New views of arc, a master regulator of synaptic plasticity. Nat Neurosci 14: $279-284$

Siegmund A, Wotjak CT. 2007. A mouse model of posttraumatic stress disorder that distinguishes between conditioned and sensitised fear. J Psychiatr Res 41: 848-860.

Sillivan SE, Joseph NF, Jamieson S, King ML, Chévere-Torres I, Fuentes I, Shumyatsky GP, Brantley AF, Rumbaugh G, Miller CA. 2017. Susceptibility and resilience to posttraumatic stress disorder-like behaviors in inbred mice. Biol Psychiatry 82: 924-933.

Song C, Moyer JR Jr. 2018. Layer- and subregion-specific differences in the neurophysiological properties of rat medial prefrontal cortex pyramidal neurons. J Neurophysiol 119: 177-191.

Spalding KN. 2018. The role of the medial prefrontal cortex in the generalization of conditioned fear. Neuropsychology 32: 1-17.

Stern CA, Gazarini L, Vanvossen AC, Hames MS, Bertoglio LJ. 2013. Activity in prelimbic cortex subserves fear memory reconsolidation over time. Learn Mem 21: $14-20$.

Thomas DA, Riccio DC. 1979. Forgetting of a CS attribute in a conditioned suppression paradigm. Anim Learn Behav 7: 191-195.

Thomas DR, Ost J, Thomas D. 1960. Stimulus generalization as a function of the time between training and testing procedures. J Exp Anal Behav 3: 9-14.

Tipps ME, Raybuck JD, Buck KJ, Lattal KM. 2014. Delay and trace fear conditioning in C57BL/6 and DBA/2 mice: issues of measurement and performance. Learn Mem 21: 380-393.
Vanvossen AC, Portes MA, Scoz-Silva R, Reichmann HB, Stern CA, Bertoglio LJ. 2017. Newly acquired and reactivated contextual fear memories are more intense and prone to generalize after activation of prelimbic cortex NMDA receptors. Neurobiol Learn Mem 137: 154-162.

Vazdarjanova A, Ramirez-Amaya V, Insel N, Plummer TK, Rosi S,

Chowdhury S, Mikhael D, Worley PF, Guzowski JF, Barnes CA. 2006.

Spatial exploration induces ARC, a plasticity-related immediate-early gene, only in calcium/calmodulin-dependent protein kinase II-positive principal excitatory and inhibitory neurons of the rat forebrain. J Comp Neurol 498: 317-329.

Vidal-Gonzalez I, Vidal-Gonzalez B, Rauch SL, Quirk GJ. 2006. Microstimulation reveals opposing influences of prelimbic and infralimbic cortex on the expression of conditioned fear. Learn Mem 13: 728-733.

Vieira PA, Lovelace JW, Corches A, Rashid AJ, Josselyn SA, Korzus E. 2014. Prefrontal consolidation supports the attainment of fear memory accuracy. Learn Mem 21: 394-405.

Waung MW, Pfeiffer BE, Nosyreva ED, Ronesi JA, Huber KM. 2008. Rapid translation of arc/Arg3. 1 selectively mediates mGluR-dependent LTD through persistent increases in AMPAR endocytosis rate. Neuron 59: 84-97.

Wiltgen BJ, Silva AJ. 2007. Memory for context becomes less specific with time. Learn Mem 14: 313-317.

Wiltgen BJ, Brown RA, Talton LE, Silva AJ. 2004. New circuits for old memories: the role of the neocortex in consolidation. Neuron 44: 101-108.

Xu W, Sudhof TC. 2013. A neural circuit for memory specificity and generalization. Science 339: 1290-1295.

Received March 15, 2018; accepted in revised form April 13, 2018. 


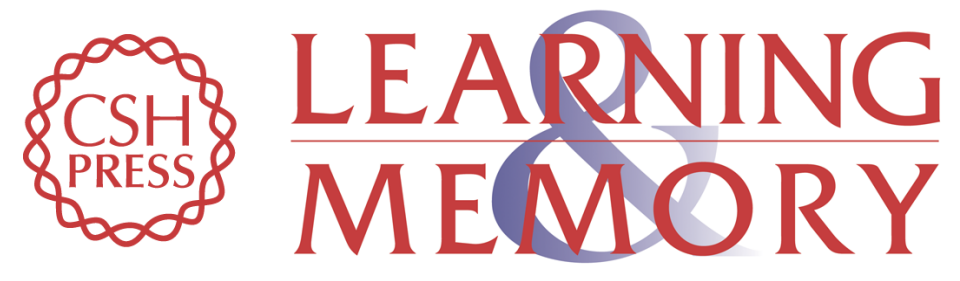

\section{Cued fear memory generalization increases over time}

Gabrielle A. Pollack, Jessica L. Bezek, Serena H. Lee, et al.

Learn. Mem. 2018, 25:

Access the most recent version at doi:10.1101//m.047555.118

Supplemental
Material http://learnmem.cshlp.org/content/suppl/2018/06/05/25.7.298.DC1

References This article cites 99 articles, 24 of which can be accessed free at: http://learnmem.cshlp.org/content/25/7/298.full.html\#ref-list-1

Creative This article is distributed exclusively by Cold Spring Harbor Laboratory Press for the Commons first 12 months after the full-issue publication date (see

License http://learnmem.cshlp.org/site/misc/terms.xhtml). After 12 months, it is available under a Creative Commons License (Attribution-NonCommercial 4.0 International), as described at http://creativecommons.org/licenses/by-nc/4.0/.

Email Alerting Receive free email alerts when new articles cite this article - sign up in the box at the Service top right corner of the article or click here. 